\title{
Structural Optimization of Concrete Slab Frame Bridges Considering Investment Cost
}

\author{
Majid Solat Yavari ${ }^{1,2}$, Costin Pacoste ${ }^{1,2}$ and Raid Karoumi ${ }^{1}$ \\ 1. Division of Structural Engineering and Bridges, Royal Institute of Technology (KTH), Stockholm 100 44, Sweden \\ 2. ELU Konsult AB, Stockholm 102 51, Sweden
}

\begin{abstract}
The present study investigates computer-automated design and structural optimization of concrete slab frame bridges considering investment cost based on a complete 3D model. Thus, a computer code with several modules has been developed to produce parametric models of slab frame bridges. Design loads and load combinations are based on the Eurocode design standard and the Swedish design standard for bridges. The necessary reinforcement diagrams to satisfy the ultimate and serviceability limit states, including fatigue checks for the whole bridge, are calculated according to the aforementioned standards. Optimization techniques based on the genetic algorithm and the pattern search method are applied. A case study is presented to highlight the efficiency of the applied optimization algorithms. This methodology has been applied in the design process for the time-effective, material-efficient, and optimal design of concrete slab frame bridges.
\end{abstract}

Key words: Slab frame bridge, structural design, structural optimization, genetic algorithm, pattern search method.

\section{Introduction}

The traditional process of structural design of concrete structures is mainly based on trial and error methods. In such a process, the designer assumes the initial configuration (e.g., concrete type, section dimensions, and reinforcement amounts) for design loads and controls the assumed configuration against the requirements of the design standard. If the section fulfills the requirements, the section is structurally approved; otherwise, the designer modifies the configuration until a satisfactory structure is achieved. This process is not only time-consuming but also raises several questions. For instance, the method does not allow for the determination of whether the assumed section is an economically optimized design or how the structure could be designed more quickly and cost-efficiently [1]. In the last decades, many researchers have examined several optimization algorithms within the structural design process to find

Corresponding author: Majid Solat Yavari, Ph.D. student, research fields: structural optimization, structural design, LCA, and structural dynamics. the optimal design of different structures. Even though optimization of complex structures can lead to great cost savings and shorten the design process, as Cohn and Thierauf [2] have stated, there is still a remarkable gap between the theoretical aspects of structural optimization and its practical use in engineering, particularly in the application of structural optimization on realistic and complex structures [3].

Cohn and Dinovitzer [4], in an extensive 1994's review based on 500 optimization examples, concluded that application of structural optimization to real-life examples was very narrow compared to the mathematical aspects of optimization. Moreover, most of the studied examples dealt with section or member optimization (e.g., beams, columns, plates, shells, etc.). Also, the majority of studied examples (88\%) considered very few static loads in the optimization process, and optimization of concrete structures made up only $4 \%$ of the whole study. Sarma and Adeli [3] have presented a wide-ranging literature review on cost optimization of concrete structures categorized in different types of concrete constructions. They have also stated that there are only a few journal articles 
focusing optimization of realistic 3D (three-dimensional) structures. Although the application of optimization in realistic examples of structural design has been recently more examined, the situation remains largely unchanged. Structural optimization of complex structures like bridges can provide significant savings in both cost and design time and therefore should be taken into particular consideration. Regarding studies in the cost optimization of bridges, the works presented in Table 1 should be mentioned.

On the other hand, the aim of structural optimization should not only be finding the cost-optimized structure but also introducing automation in the structural design process. Templeman [5] has studied the usage of structural optimization software in design offices and tried to examine the benefits of implementing computational optimization methods. Referring to the lack of practical optimization software at that time (1983), Templeman recommends more cooperation between researchers and design offices to develop user-friendly and proficient structural optimization software with a focus on practical design problems in order to establish more time- and cost-effective and more productive design procedures. Among the first efforts of computer-automated design, Aguilar, Movassaghi and Brewer [6], researchers at the Louisiana State University, in collaboration with the Louisiana Department of Highways, developed a computer program for design and optimization of highway bridges. In another application of structural optimization and automated design, Moharrami and Grierson [7] presented a computerized method (the so-called optimal criteria method), for optimization of two-dimensional reinforced concrete building frameworks. In this method, the cross-section dimensions and longitudinal reinforcement giving the minimum cost of the structure are found.

In the present work, complete automated design and structural optimization are performed on realistic $3 \mathrm{D}$ models of concrete slab frame bridges. Concrete slab frame bridges or integral portal frame bridges can be built either as single or multiple spans with open or closed foundation slabs on rock, packed soil, or piles. Advantages of slab frame bridges include relatively simple design, fast construction, and easy maintenance due to the smaller number of structural elements and lack of expansion joints. These bridges are frequently used in many countries and are one of the most common types of bridges in Sweden, especially for short spans [8, 9]. According to the Swedish Transport Administration (Trafikverket) database, slab frame bridges constitute almost $46 \%$ of all the bridges in Sweden [9, 10]. Fig. 1 shows a typical slab frame bridge in Sweden [11]. The current research is the first study, to the best of the authors' knowledge, of the structural optimization of complete 3D models of slab frame bridges. Furthermore, the most

Table 1 Researches on cost optimization of bridges.

\begin{tabular}{ll}
\hline Author(s) & Research \\
\hline Torres et al. [12] & $\begin{array}{l}\text { Optimization of prestressed concrete highway bridges } \\
\text { Cost minimization of a prestressed concrete box bridge girder used in a balanced cantilever bridge } \\
\text { Yu et al. [13] }\end{array}$ \\
Barr, Sarin and Bishara [14] & $\begin{array}{l}\text { Cost minimization of a continuous three-span bridge RC (reinforced concrete) slab of 16.6 m span } \\
\text { length using the general geometric programming method }\end{array}$ \\
Lounis and Cohn [15] & $\begin{array}{l}\text { Optimization of short and medium span highway bridges consisting of reinforced concrete slabs on } \\
\text { concrete I-girders }\end{array}$ \\
Cohn and Lounis [16] & $\begin{array}{l}\text { Application of multilevel and multi-criteria optimization of concrete bridge systems } \\
\text { Cost optimization of prestressed I-girder bridges }\end{array}$ \\
Fereig [17] & $\begin{array}{l}\text { Cost optimization of precast, prestressed concrete I-beam bridge systems using the robust neural } \\
\text { dynamics model of Adeli and Park }\end{array}$ \\
Sirca and Adeli [18] & $\begin{array}{l}\text { Cost optimization of 2D reinforced concrete box frames used in road constructions } \\
\text { Cost optimization of cross-section of prestressed concrete precast pedestrian bridges by using SA } \\
\text { Perea et al. [19, 20] }\end{array}$ \\
Martí and Vidosa [21] & Parametric study using the threshold acceptance method to find cost-optimum road frame bridges \\
Perea et al. [22] &
\end{tabular}




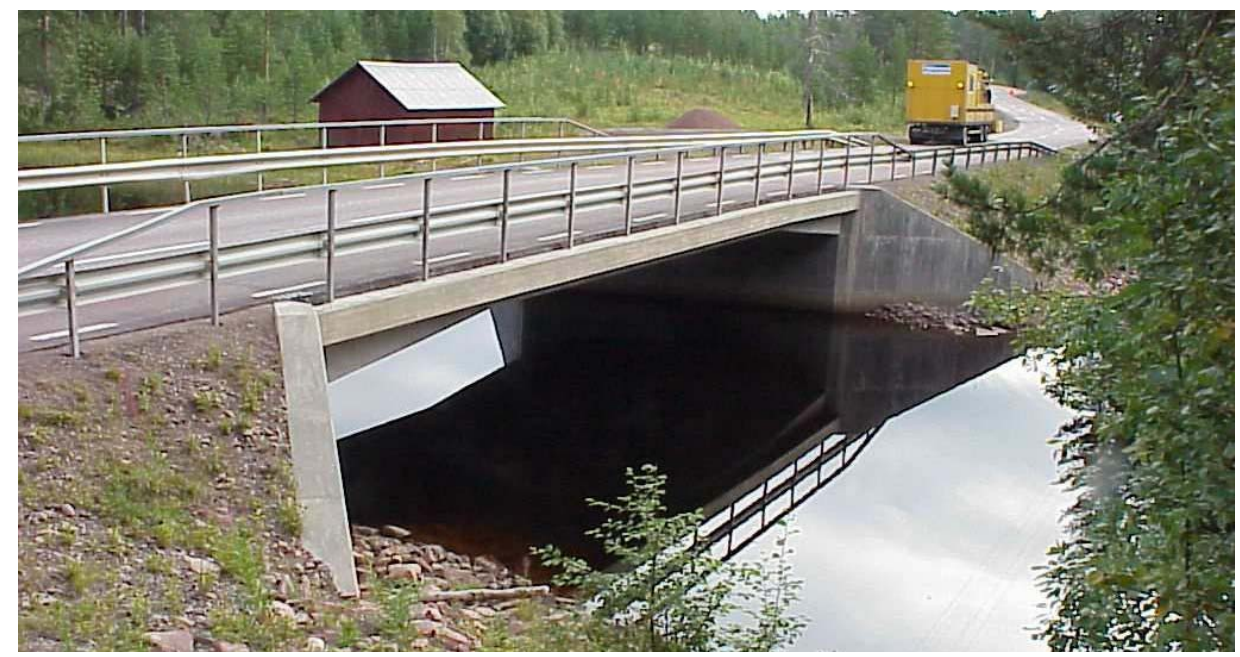

Fig. 1 Typical slab frame bridge over a river in Sweden [11].

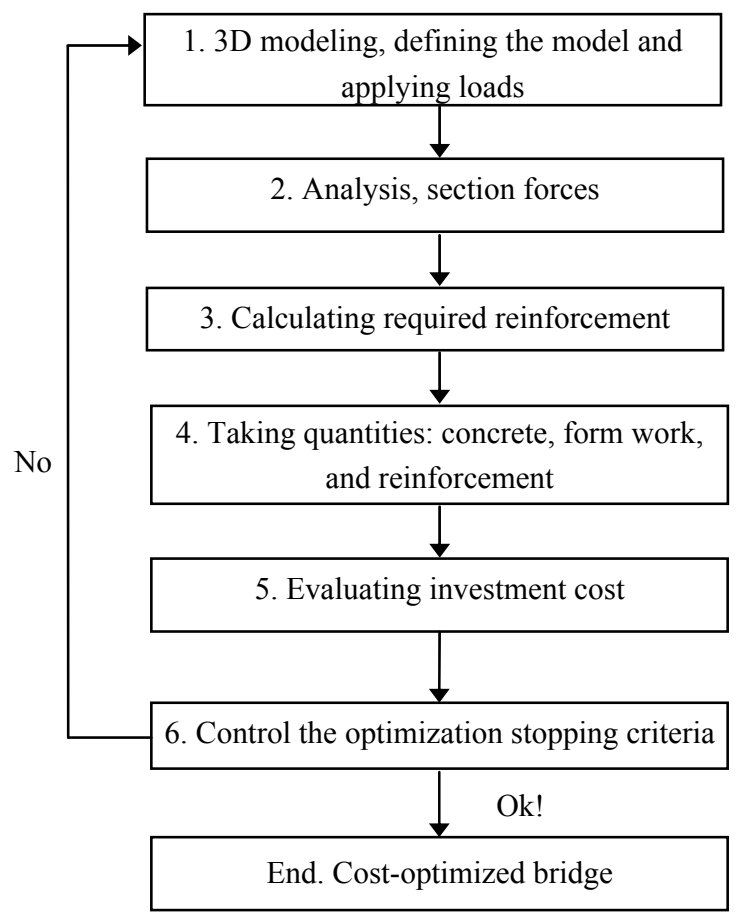

Fig. 2 The automated design and optimization process.

important feature of this research is its focus on whole structural optimization of realistic and complete models of slab frame bridges rather than optimization of individual members and sections. The results of this research will contribute to time-effective, material-efficient, and optimal design of concrete slab frame bridges.

\section{Design and Optimization Process}

In this work, a computer code with several modules has been developed to produce parametric models of slab frame bridges. Fig. 2 presents the applied automated design and iterative optimization process. Module 1 includes modeling and applying all relevant loads. In Module 2, analysis is performed and section forces and load combinations are extracted. The resulting section forces and stresses are computed in $3 \mathrm{D}$ in the commercial finite element program Abaqus Ver. 6.12. Design loads and load combinations are based on the Eurocode standard and the Swedish design standard for bridges. Module 3, in a separately developed program, calculates the necessary reinforcements to satisfy ULS (ultimate limit state), SLS (serviceability limit state), fatigue checks, and other design and constructability requirements for the whole bridge (constraints). In the next modules, the quantities of concrete, formwork, and reinforcements, as well as total investment cost of the bridge (objective function), based on unit costs defined by the user, are calculated. This process is performed by optimization algorithms in an iterative procedure until the stopping criterion is met.

A very significant step in solving an optimization problem is choosing a suitable optimization algorithm. There are many ways to solve optimization problems. Optimization methods are usually divided into two major groups as follows:

(1) Minimum seeking or mathematical-based 
algorithms: these algorithms are traditional gradient-based methods, which are fast but easily trapped in local minima;

(2) Metaheuristic or stochastic methods: these methods generally use probabilistic calculations and do not use the gradient or Hessian matrix of the objective function. They are usually slower but more successful at finding the global minimum.

In this research, there are nonlinear constraints, and the objective function is stochastic and discontinuous and the gradients of the objective function are undefined. On the other hand, the process of calculating necessary reinforcement and the objective function are done in external programs like a so-called "black box"; consequently, optimization algorithms that use only objective function values to find the optimum value are preferable. Based on the characteristics of the optimization problem, two algorithms, GA (genetic algorithm) and PS (pattern search) have been implemented in the optimization process and a comparison between the results obtained from the two methods is presented. GA and PS are robust and efficient methods and are useful for problems not easily solved using mathematical- and gradient-based algorithms. They both perform very well for optimization problems that are discontinuous and stochastic and problems with discrete or random data. The MATLAB optimization toolbox has been used for the optimization.

\subsection{Pattern Search Method}

Direct search methods generally refer to optimization methods used to solve problems where the objective function is not continuous and differentiable. They examine only the objective function in a stochastic or non-stochastic strategy to obtain a best solution from earlier results. This description of direct search suits many different algorithms used today and is sometimes considered a common term for optimization algorithms that use objective function values rather than gradients of objective functions [23, 24]. Direct search was first introduced and established by Hooke and Jeeves [25] and has been widely applied since that time. All direct search methods are based on approaches that produce variations of the parameter vectors and then select better values, i.e., with a lower objective function value, among the newly generated parameters.

In this research, an optimization method called pattern search in the MATLAB toolbox, which is under the category of direct search methods, has been implemented. At each iteration, the pattern search method generates a set of points (variables), creating a "mesh", by adding the current point to some vectors, which is called the pattern. The pattern search method examines this set of points, searching for one with a lower objective function value ("polling"). If the algorithm finds a point in the new mesh with a lower objective function value, this point becomes the current point for the next step; otherwise, the algorithm generates and examines a new set of points around the current point. This process continues until the stopping criterion is met. There are several strategies to produce patterns to generate a new mesh. While this research implemented and compared all these strategies, the results of the GPS (generalized pattern search), which uses "fixed-direction" vectors to make the pattern, is presented [26].

\subsection{GA (Genetic Algorithm)}

The genetic algorithm was developed by John Holland and his colleagues in the 1960s with the goal of creating a search method that was more robust and coherent than the most widely used methods at that time. The creators of GA were inspired by nature and Darwin's theory of evolution [27]. For almost 50 years now, it has been proven to be a robust algorithm through other theories of optimization and their empiric results. GA can be used to solve complex problems because it uses values of the objective function where it is not required to have knowledge about the function itself and the mathematical gradients 
[28]. The GA is based on techniques inspired by natural evolution and principles of genetics, like inheritance, selection, mutation, and crossover. GA starts by generating an initial population and calculating their objective function values. The next step is to select "parents" with lower objective function values. Some of the individuals in the population with the lower objective function value, the "elite," will pass to the next population. The next step is to produce "children" from the parents by mutation or crossover techniques to create the next generation until the stopping criterion is met [26].

\section{Optimization Problem}

An optimization problem has three main parts, the variables, constraints, and objective function, and can be expressed in mathematical form as follows:

Input variables: $x=\left[x_{1}, x_{2}, \ldots, x_{n}\right] \in R^{n}$

Constraints: $g_{i}(x) \leq 0, i=1,2, \ldots, m$

$h_{j}(x)=0, j=1,2, \ldots, r$

Objective function: minimize $f(x)$

In this work, the input variables include dimensions of bridge elements and concrete type (among three concrete types). Fig. 3 shows a 2D section of a slab frame bridge consisting of different variables and constant parameters. In this study, concrete type, thickness of the slab mid-span (Tf1), thickness of the slab beside the haunches (Tf2), thickness of frame legs beside foundations $(\operatorname{Tr} 1)$, thickness of frame legs beside haunches ( $\operatorname{Tr} 2)$, thickness of wing walls beside frame legs $(T w 1)$, thickness of wing walls at the end ( $T w 2)$, width of haunches $(B f 1)$, and height of haunches (Hf 1 ) have been considered as independent input variables. Furthermore, the required reinforcement areas in every mesh element of each part of the bridge have been considered as dependent variables and are calculated in a separate program to fulfill the constraints. In the presented case study, the bridge geometry is assumed symmetric and optimization is performed on the deck, frame legs, and wing walls. Other parts of the bridge (e.g., foundation slabs) can also be included in the structural optimization process, but in the current case study, they have been checked for overturning, slipping, and soil capacity and are considered constant.

In this research, the required reinforcement area in each member $\left(A_{S}\right)$ is used instead of detailed topology of the reinforcement (number, diameter, longitudinal distribution of the steel bars, etc.). Using the required reinforcement amounts as the design variables for steel reinforcement instead of detailed reinforcement patterns, which are irrelevant and unnecessary especially in the first stages of the design process, will dramatically decrease the number of input variables

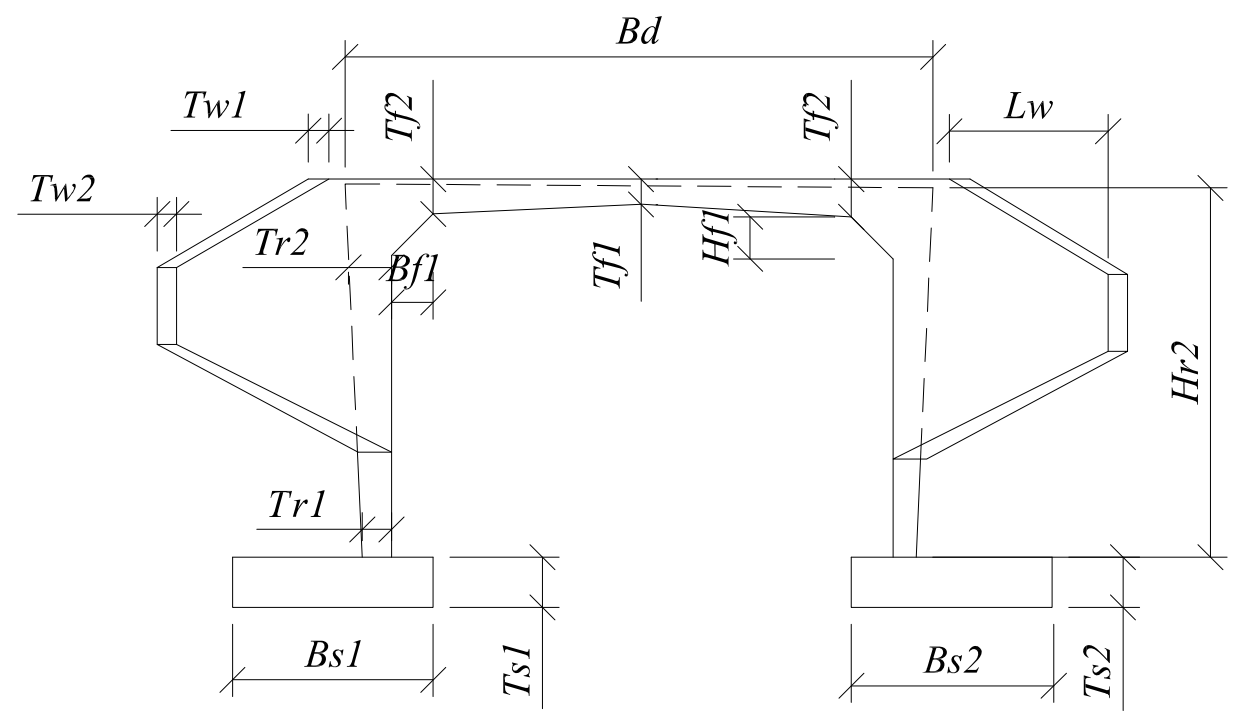

Fig. 3 Variables and constant parameters. 
and hence the algorithm convergence time. This simplification is in correspondence with the results of Balling and Yao's [29] work. Balling and Yao studied the optimization of three-dimensional reinforced concrete frames and compared the results of optimization with two different assumptions for reinforcement design variables. In the first assumption, the traditional method, they considered the area of reinforcement in each member $\left(A_{s}\right)$ as the only design variable for steel reinforcement. In the second assumption, they also included the topology of reinforcement (number, diameter, and longitudinal distribution of steel bars) into a multilevel optimization process. By comparing the obtained results, they showed that the traditional method is much quicker at finding the optimum values but that the optimum values and objective cost in the two assumptions are very similar. They further verified that the optimum concrete section dimensions are insensitive to the reinforcement pattern.

\subsection{Constraints}

All design requirements of ULS, SLS, and fatigue control based on the Eurocodes [30], and the Swedish annex for design of bridges (TRVK Bro 11) [31], have been considered as constraints. Minimum and maximum thickness of each member, minimum required reinforcement, minimum space between steel bars, and other constructability constraints according to the aforementioned standards have also been considered.

\subsection{Objective Function}

In this study, cost of material, procurement, and execution of concrete, reinforcement, and form working for the bridge deck, frame legs, and wing walls have been considered. The objective function is shown in Eq. (1). The extra factor in Eq. (1) is based on practical experience in design, assumed to be 1.4 for considering the anchorage length of reinforcements and extra reinforcements due to details.

$$
\begin{array}{r}
f(x)=\text { Cost }_{\text {concrete }}+\text { Cost }_{\text {form work }}+ \\
\text { extra factor }
\end{array}
$$

Moreover, thinner concrete section thicknesses imply higher amounts and more dense reinforcement with smaller spaces between bars, resulting in higher construction time and labor work; therefore, the thickness of different parts has been considered as an indicator for the constructability factor. Consequently, a factor on reinforcement work based on the thickness of each element has been introduced. Table 2 presents detailed unit prices and constructability factors acquired from constructing companies in Sweden.

\subsection{Stopping Criteria}

Stopping criteria in optimization define the point at which the calculation can be stopped, terminating the process of finding the optimum value. In the aforementioned process, the stopping criteria are defined by the user and can be, for example, a maximum number of iterations or function evaluations, convergence of the objective function or input variables, a calculation time limit, etc. It is important to select proper stopping criteria for each optimization problem. However, it should be considered that, in practical engineering, it is often more important to have solutions that improve the initial design as desired rather than finding the lowest objective function value. In other words, in practical problems, we often desire to find a solution that is "good enough" in a specific time domain rather than finding the global optimum [32]. Hence, in the following case study, a total time of $10 \mathrm{~h}$ or function tolerance (alteration in the objective function value in two successive iterations) and mesh size of less than 0.05 have been considered as stopping criteria (depending on which criterion is fulfilled sooner) in the PS method. Subsequently, the stopping criteria for the GA are adjusted considering the stopping criteria that were met quicker in PS. Accordingly, the results of the two algorithms are based on the same stopping criteria and assumptions and can be compared. 
Table 2 Unit prices and constructability factors.

\begin{tabular}{lll}
\hline Description & Unit & Value \\
\hline Concrete material C32/40, $f_{c}=32 \mathrm{MPa}$ & $\mathrm{SEK} / \mathrm{m}^{3}$ & 1,700 \\
Concrete material C35/45, $f_{c}=35 \mathrm{MPa}$ & $\mathrm{SEK} / \mathrm{m}^{3}$ & 1,800 \\
Concrete material C50/60, $f_{c}=50 \mathrm{MPa}$ & $\mathrm{SEK} / \mathrm{m}^{3}$ & 2,000 \\
Concrete work of wing walls $\left(2 h / \mathrm{m}^{3}\right)$ & $\mathrm{SEK} / \mathrm{m}^{3}$ & 1,000 \\
Concrete work of frame legs $\left(1.5 h / \mathrm{m}^{3}\right)$ & $\mathrm{SEK} / \mathrm{m}^{3}$ & 750 \\
Concrete work of bridge deck $\left(2 h / \mathrm{m}^{3}\right)$ & $\mathrm{SEK} / \mathrm{m}^{3}$ & 800 \\
Extra work for concrete C50/60 & $\mathrm{SEK} / \mathrm{m}^{3}$ & 200 \\
Formwork of wing walls on straight walls $\left(250 \mathrm{SEK}+2 h / \mathrm{m}^{2}\right)$ & $\mathrm{SEK} / \mathrm{m}^{2}$ & 1,250 \\
Formwork of wing walls on variable thickness $\left(350 \mathrm{SEK}+3 h / \mathrm{m}^{2}\right)$ & $\mathrm{SEK} / \mathrm{m}^{2}$ & 1,850 \\
Formwork of frame legs on straight walls $\left(200 \mathrm{SEK}+1.5 h / \mathrm{m}^{2}\right)$ & $\mathrm{SEK} / \mathrm{m}^{2}$ & 1,000 \\
Formwork of frame legs on variable thickness $\left(300 \mathrm{SEK}+2 h / \mathrm{m}^{2}\right)$ & $\mathrm{SEK} / \mathrm{m}^{2}$ & 1,300 \\
Formwork of deck on straight thickness $\left(500 \mathrm{SEK}+1.5 h / \mathrm{m}^{2}\right)$ & $\mathrm{SEK} / \mathrm{m}^{2}$ & 1,250 \\
Formwork of deck on variable thickness $\left(500 \mathrm{SEK}+2 h / \mathrm{m}^{2}\right)$ & $\mathrm{SEK} / \mathrm{m}^{2}$ & 1,500 \\
Reinforcement material & $\mathrm{SEK} / \mathrm{kg}^{2}$ & 9 \\
Reinforcement work in wing walls $(35 h / \mathrm{t})$ & $\mathrm{SEK} / \mathrm{kg}$ & 17.5 \\
Reinforcement work in frame legs $(30 h / \mathrm{t})$ & $\mathrm{SEK} / \mathrm{kg}$ & 15 \\
Reinforcement work in bridge deck $(35 h / \mathrm{t})$ & $\mathrm{SEK} / \mathrm{kg}$ & 17.5 \\
Factor on reinforcement work considering straight thickness & - & 1 \\
Factor on reinforcement work considering variable thickness & - & 1.15 \\
Factor on reinforcement work $($ thickness $<40 \mathrm{~cm})$ & - & 1.2 \\
Factor on reinforcement work $(40 \mathrm{~cm} \leq$ thickness $<60 \mathrm{~cm})$ & - & 1.1 \\
Factor on reinforcement work $(60 \mathrm{~cm} \leq$ thickness $)$ & - & 1 \\
\hline
\end{tabular}

*One SEK (Swedish Kron) $\approx 0.11$ euro $(€)$.

\section{Application to a Case Study}

In a preliminary study done by the authors [1] comparing the optimized bridge results with a previously constructed bridge by considering simple assumption and unit costs, the optimization algorithms showed substantial potential savings in materials and costs. The best results were achieved using the PS algorithm, which showed a cost reduction of $20 \%$ compared to the initial design. For the current study, the complete design automation and optimization process have been applied to several real case projects before their construction.

The case study presented here is the Sadjemjoki Bridge, which is a road bridge located on road number 941 in Norrbotten County, Sweden. The bridge was optimally designed in 2015 according to the aforementioned process and is now in service. The Sadjemjoki Bridge is an open foundation slab frame bridge. The total bridge length is $11.45 \mathrm{~m}$, free opening of the bridge is $6 \mathrm{~m}$, free height is $3.25 \mathrm{~m}$, and free width is $7 \mathrm{~m}$ with no deck skewness. The bridge is symmetrical in both longitudinal and transversal directions; hence, the input variables are presented for one frame leg and wing wall and they are the same for the other frame leg and wing walls. Fig. 4 shows the preliminary sketch of the bridge. Design parameter values and the considered loads and their corresponding values for the structural design of the bridge are presented in Table 3 . The bridge has been optimally designed to the requirements of ULS, SLS, and fatigue control according to the Eurocodes [30], and the Swedish annex for design of bridges (TRVK Bro 11) [31].

For the Sadjemjoki Bridge, the initial population size for GA is 18. Moreover, the elite count, which defines the numbers of individuals in the population size that have the smallest objective function value and stay in the next generation, is set to five. Crossover fraction, 


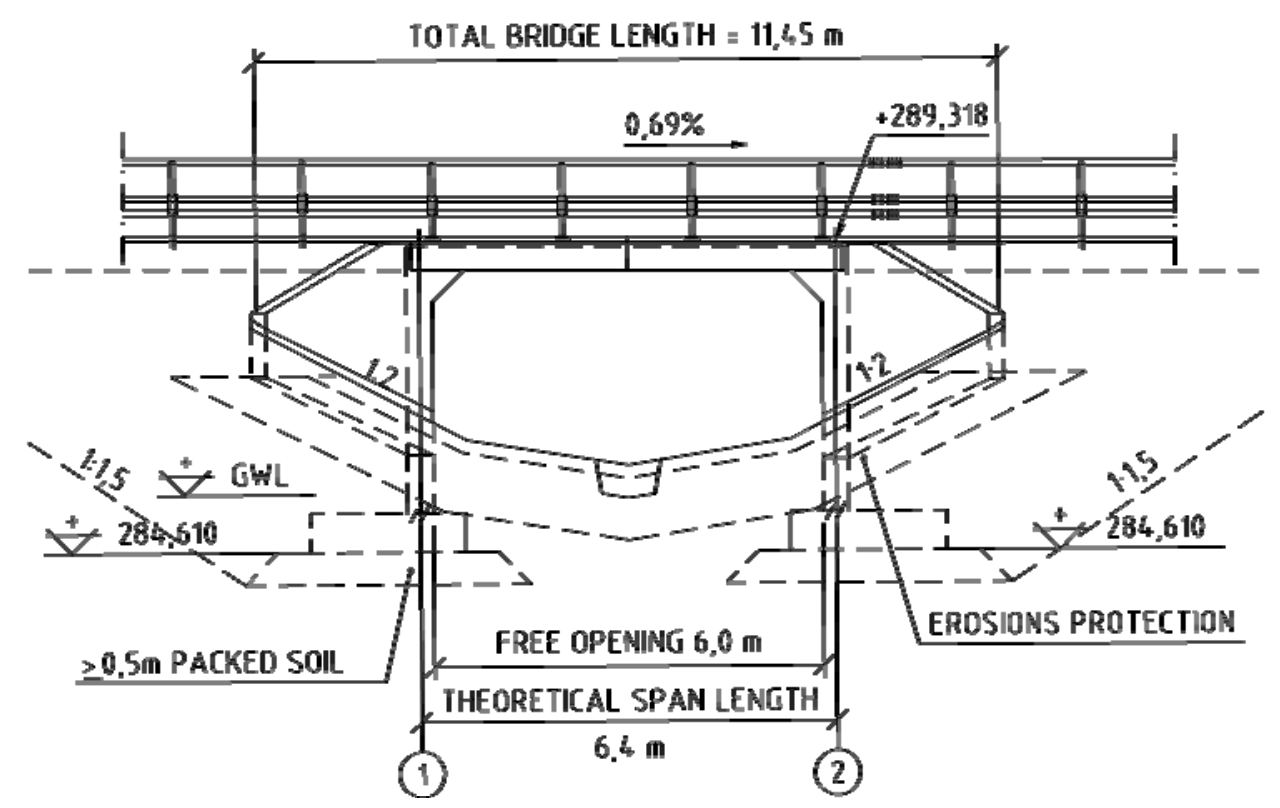

Fig. 4 Sketch of the Sadjemjoki Bridge.

Table 3 Design parameters and load assumptions.

\begin{tabular}{|c|c|}
\hline \multicolumn{2}{|l|}{ Design and load assumptions } \\
\hline Reinforcement type & B500B \\
\hline Foundation & $0.5 \mathrm{~m}$ packed soil, modeled as springs \\
\hline Safety class & 2 \\
\hline Life time & 80 years \\
\hline Exposure class & XD1/XF4 except upper side of the deck: XD3/XF4 \\
\hline Dead weight & $\gamma_{\text {concrete }}=25 \mathrm{kN} / \mathrm{m}^{3}$ \\
\hline Overburden & $\gamma_{\text {soil,dry }}=18 \mathrm{kN} / \mathrm{m}^{3}, \gamma_{\text {soil,wet }}=11 \mathrm{kN} / \mathrm{m}^{3}$ \\
\hline Average ground water level & $H_{w}=0.9 \mathrm{~m}$ above foundation lower side \\
\hline Surfacing & $Q_{\text {surfacing }}=1.75 \mathrm{kN} / \mathrm{m}^{2}$ \\
\hline Even increase in temperature & $\Delta T=31^{\circ}$, creep ratio $=0.28$ \\
\hline Even decrease in temperature & $\Delta T=-41^{\circ}$, creep ratio $=0.28$ \\
\hline Uneven increase in temperature & $T_{\max }=6.6^{\circ}, T_{\min }=-6.6^{\circ}$, creep ratio $=0.28$ \\
\hline Uneven decrease in temperature & $T_{\max }=4^{\circ}, T_{\min }=-4^{\circ}$, creep ratio $=0.28$ \\
\hline Shrinkage & Applied as decrease in temperature by $25^{\circ}$, creep ratio $=1.5$ \\
\hline Road traffic load & Load Models 1 and 2 and classification traffic vehicles \\
\hline Surcharge & $\mathrm{P}=20 \mathrm{kN} / \mathrm{m}^{2}, k_{0}=0.34$, rectangular constant distribution \\
\hline Earth pressure & $k_{0}=0.39, \gamma_{d r y}=18 \mathrm{kN} / \mathrm{m}^{3}, \gamma_{\text {wet }}=11 \mathrm{kN} / \mathrm{m}^{3}$ \\
\hline Braking force & Total force $=255 \mathrm{kN}$, imposed on the whole deck \\
\hline Traffic lateral force & Total force $=64 \mathrm{kN}$, imposed on the whole deck \\
\hline Support yielding & Vertical and horizontal on each support, $0.01 \mathrm{~m}$ \\
\hline Guardrail load & Linear load magnitude on each edge beam: $0.5 \mathrm{kN} / \mathrm{m}$ \\
\hline Wind load on traffic & Traffic profile height $=2.6 \mathrm{~m}$, load pressure: $1.3 \mathrm{kN} / \mathrm{m}^{2}$ \\
\hline Wind load on structure & Imposed structure height $=1.8 \mathrm{~m}$, load pressure: $1.2 \mathrm{kN} / \mathrm{m}^{2}$ \\
\hline Resistant earth pressure & Applied on frame legs \\
\hline Fatigue load cycle & 50,000 ; average daily traffic in a year: 5,000 \\
\hline
\end{tabular}


which defines the portion of the next generation created by crossover (merging the parents' vectors), has been set to 0.5 . The rest of the population in the next generation is produced by random alterations (mutation) in the individuals to have more diversity in the next generation and to explore wider space for the optimum value.

Fig. 5 displays typical cost variation in the PS optimization algorithm. In the PS algorithm, the stopping criterion which was fulfilled more quickly was the function tolerance and the mesh size, with a total calculation time of $9.5 \mathrm{~h}$. Subsequently, the stopping criteria for GA were adjusted considering the same stopping criteria as PS (i.e., total calculation time of $9.5 \mathrm{~h}$ and function tolerance of 0.05 ) to have similar assumptions for comparing the results. In GA, at each iteration, instead of single points, the algorithm evaluates a population size, so although GA explores a broader domain to find the optimum, it is more time-consuming. Consequently, the stopping criterion that was fulfilled more quickly in GA was total calculation time, and the objective function value (total cost) was bigger than for the PS method. Table 4 summarizes the obtained results for optimum variables and the total cost for the two algorithms. As can be seen, the PS algorithm has better efficiency in a specific time domain compared to the GA. Thus, the Sadjemjoki Bridge was constructed based on the results of the PS algorithm.

As previously mentioned, in the optimization design process, we considered the necessary reinforcement area to fulfill the requirements of ULS, SLS, and fatigue control in every mesh element of each part of the bridge instead of using a detailed reinforcement pattern. After obtaining the optimum values, the designer will assemble the reinforcement pattern based on the necessary reinforcement diagrams. For instance, Fig. 6 shows the necessary reinforcement diagram of the bridge deck on the upper side and lower side in the longitudinal and transversal directions. The vertical axis of the diagrams shows the amount of necessary reinforcement area in $\mathrm{mm}^{2}$ per direction length $(\mathrm{m})$. Fig. 7 displays the reinforcement sketch of the bridge deck, assembled based on the necessary reinforcement diagrams.

The design optimization has been performed on two other slab frame bridges and they are also now in service. Fig. 8 shows the "cost-optimally designed" Sadjemjoki Bridge in service.

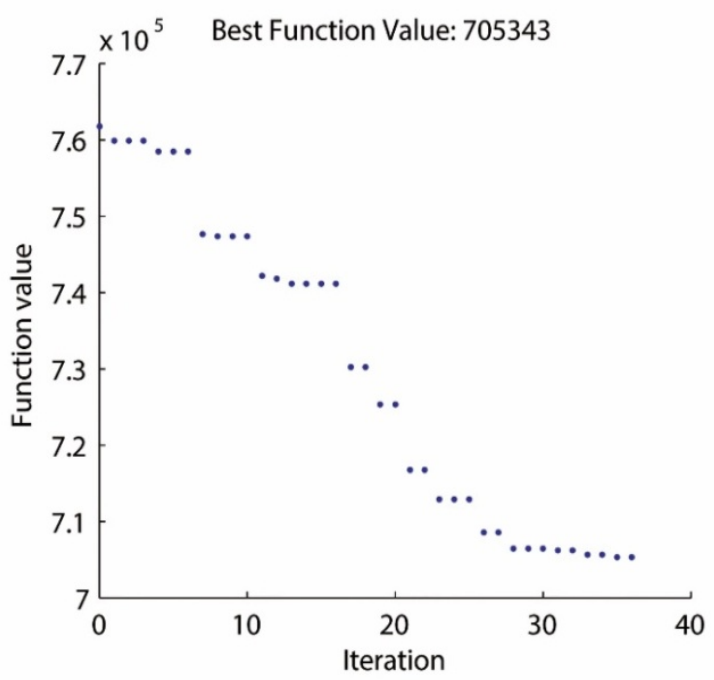

Fig. 5 Cost variation in the pattern search method.

Table 4 Summary of the results.

\begin{tabular}{lllllllllll}
\hline Algorithm & $T f 1(\mathrm{~m})$ & $T f 2(\mathrm{~m})$ & $\operatorname{Tr} 1(\mathrm{~m})$ & $\operatorname{Tr} 2(\mathrm{~m})$ & $H f 1(\mathrm{~m})$ & $B f 1(\mathrm{~m})$ & $T w 1(\mathrm{~m})$ & $T w 2(\mathrm{~m})$ & $\begin{array}{l}\text { Concrete } \\
\text { type }\end{array}$ & $\begin{array}{l}\text { Cost } \\
\text { (SEK) }\end{array}$ \\
\hline PS & 0.4 & 0.4 & 0.4 & 0.4 & 0.5 & 0.5 & 0.3 & 0.3 & C 35/45 & 705,343 \\
GA & 0.45 & 0.45 & 0.45 & 0.50 & 0.8 & 0.3 & 0.4 & 0.35 & C $35 / 45$ & 725,390 \\
\hline
\end{tabular}




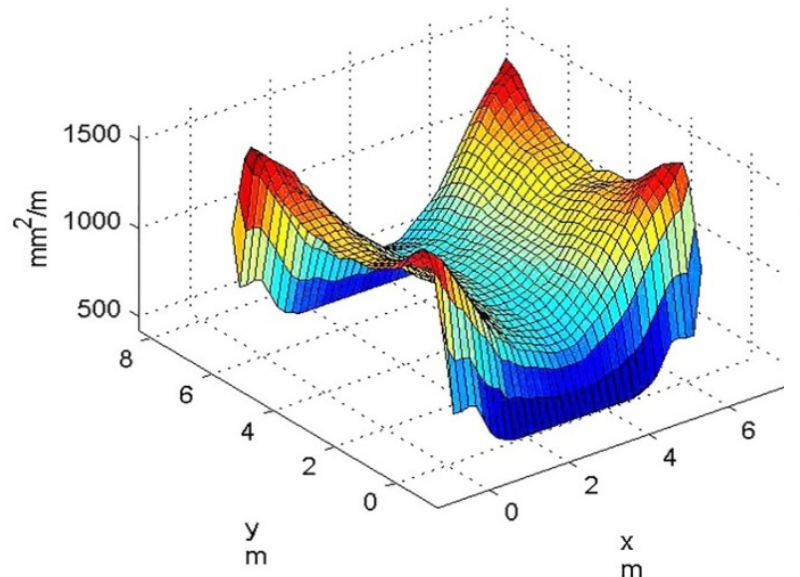

(a)

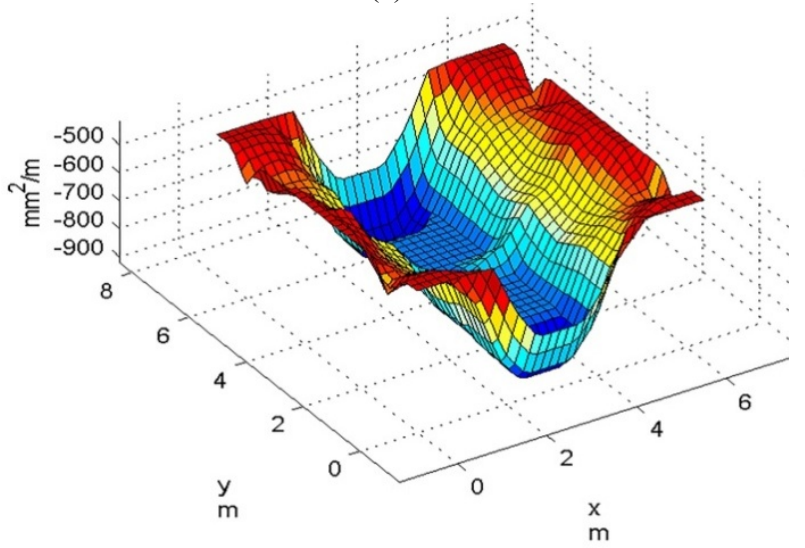

(c)

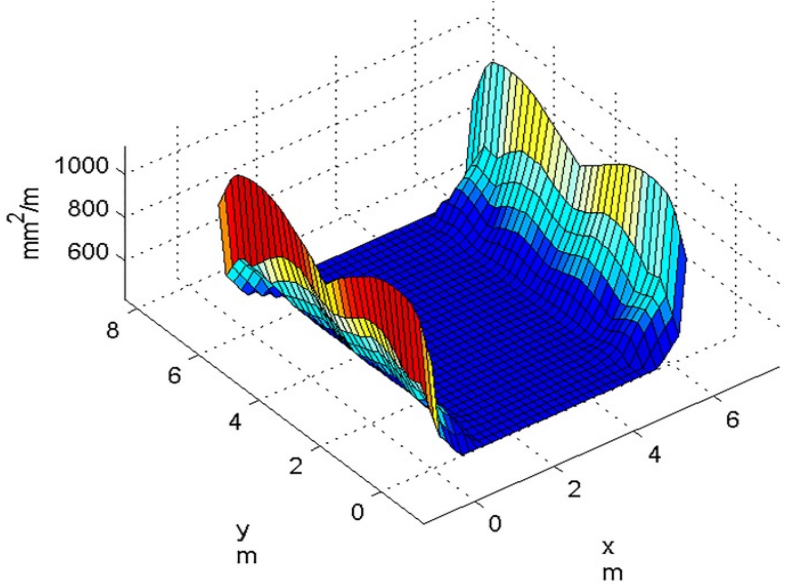

(b)

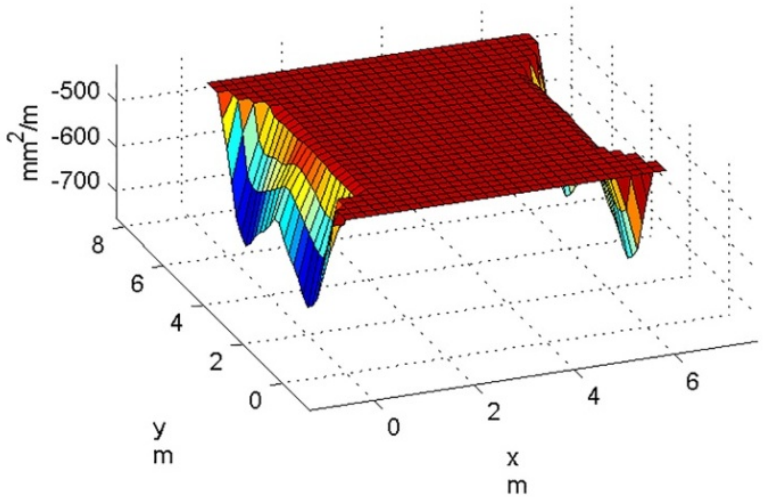

(d)

Fig. 6 Required reinforcement area in the bridge deck: (a) upper side, longitudinal (x) direction; (b) upper side, transversal (y) direction; (c) lower side, longitudinal direction; and (d) lower side, transversal direction.

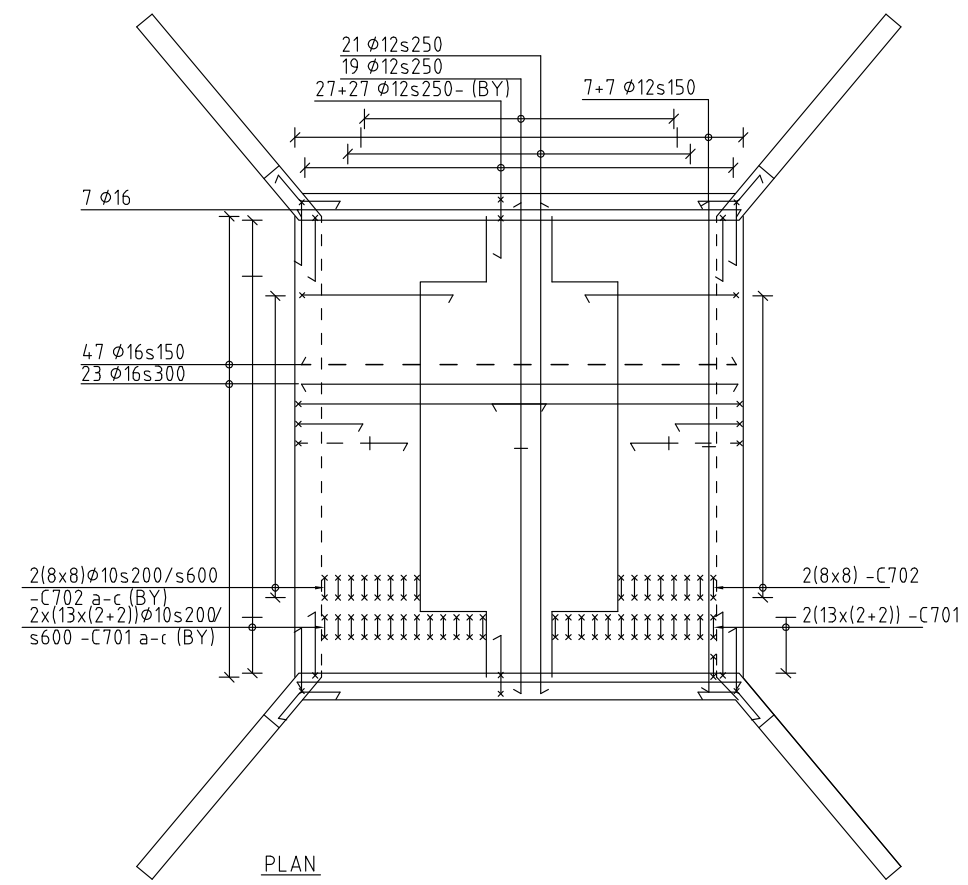

Fig. 7 Reinforcement sketch of the optimized bridge deck based on the required reinforcement area diagrams. 


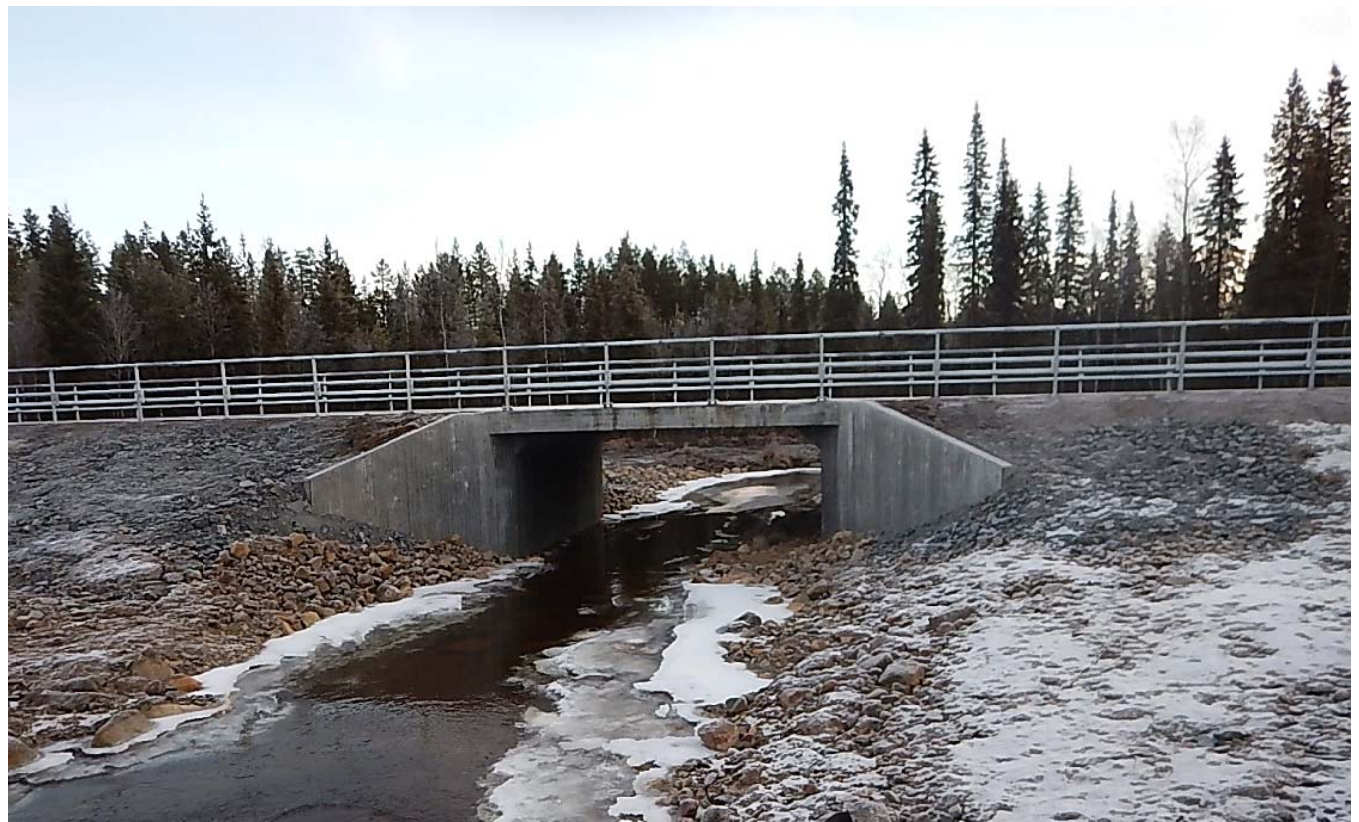

Fig. 8 The optimized Sadjemjoki Bridge in service [33].

\section{Conclusions}

In this study, complete automated design and structural optimization are performed on a realistic 3D model of concrete slab frame bridges. In summary, the following can be concluded:

Computer-automated design and cost optimization in the structural design of slab frame bridges could efficiently be implemented and applied. The obtained results showed the efficiency of the applied algorithms on the cost optimization of slab frame bridges.

Considering the high costs of calculation time in the engineering consulting sector, it is essential to have a "good enough" solution in a reasonable time domain. Therefore, choosing the proper optimization algorithm and stopping criteria in structural design optimization in real projects, especially in the case of time-consuming calculations, is very important. Because pattern search, at each iteration, evaluates single points instead of population points, as in the genetic algorithm, the pattern search method is very time-effective and robust, particularly in the case of small numbers of variables and time-consuming objective function calculations.

In the case study presented here, despite the fact that the genetic algorithm explored more space to find the optimal value, pattern search was more efficient to optimize the bridge considering a specific time period as the stopping criterion.

The presented methodology has been applied to the design process for a time-effective and cost-optimal design of concrete slab frame bridges. However, a sustainable bridge design is not only determined by criteria such as cost but also by environmental performance. In future research, the authors, by integrating LCA (life cycle assessment) with the design optimization procedure, will investigate the optimization of bridge environmental impacts to find more sustainable, time-effective, material-efficient, and economic bridge solutions.

\section{Acknowledgments}

The authors want to express their best gratitude to the Swedish consulting company, ELU Konsult AB, and the Swedish Transport Administration (Trafikverket), for financial and technical support of this project; also Christoffer Svedholm and Joakim Wallin for their contribution in the development of the "optimal bridge design" program. 


\section{References}

[1] Yavari, M. S., Pacoste, C., and Karoumi, R. 2014. "Structural Optimization of Slab Frame Bridges Using Heuristic Algorithms." Presented at the International Conference on Engineering and Applied Science Optimization, Kos, Greece.

[2] Cohn, M. Z., and Thierauf, G. 1997. "Structural Optimization.” J. Engineering Structures 19: 287-8.

[3] Sarma, K., and Adeli, H. 1998. "Cost Optimization of Concrete Structures.” J. Struct.Eng. 124: 570-8.

[4] Cohn, M. Z., and Dinovitzer, A. S. 1994. "Application of Structural Optimization.” J. Struct. Eng. 120: 617-50.

[5] Templeman, A. B. 1983. "Optimization Methods in Structural Design Practice.” J. Struct. Eng. 109: 2420-33.

[6] Aguilar, R. J., Movassaghi, K., and Brewer, J. A. 1973. "Computerized Optimization of Bridge Structures." $J$. Computers \& Structures 3: 429-42.

[7] Moharrami, H., and Grierson, D. E. 1993. "Computer-Automated Design of Reinforced Concrete Frameworks.” J. Struct. Eng. 119: 2036-58.

[8] Sundquist, H. 2008. Infrastructures Structures, Report 116. KTH, Stockholm, Sweden.

[9] Yavari, M. S., Johansson, C., Pacoste, C., and Karoumi, R. 2014. "Analysis of Slab Frame Bridges for High-Speed Trains, Some Practical Modelling Aspects." International Journal of Railway Technology 3 (2): 23-38.

[10] Johansson, C., Arvidsson, T., Martino, D., Yavari, M. S., Andersson, A., Pascote, C., and Karoumi, R. 2011. Höghastighetsprojekt_Bro:Inventering av Järnvägsbroar för Ökad Hastighet på Befintliga Banor (High Speed Train Project: Investigation of Current Railway Bridges for Speed Increase), Report 141. Division of Structural Engineering and Bridges, KTH, Stockholm, Sweden. (in Swedish)

[11] The Swedish Transport Administration (Trafikverket), Bridge and Tunnel Management (BaTMan). 2008. KodförteckningochbeskrivningavBrotyper (Code terms and Description of Bridge Types). Sweden.

[12] Torres, G. G. B., Brotchie, J. F., and Cornell, C. A. 1966. "A Program for the Optimum Design of Prestressed Concrete Highway Bridges.” PCI J. 11 (3): 63-71.

[13] Yu, C. H., Das Gupta, N. C., and Paul, H. 1986. "Optimization of Prestressed Concrete Bridge Girders." $J$ Engineering Optimization 10 (1): 13-24.

[14] Barr, A. S., Sarin S. C., Bishara A. G. 1989. "Procedure for Structural Optimization.” ACI Struct. J. 86 (5): 524-31.

[15] Lounis, Z., and Cohn, M. Z. 1993. "Optimization of Precast Prestressed Concrete Bridge Girder Systems.” PCI J. 38 (4): 60-78.

[16] Cohn, M. Z., and Lounis, Z. 1994. "Optimal Design of
Structural Concrete Bridge Systems.” J. Struct. Eng. 120: 2653-74.

[17] Fereig, S. M. 1996. "Economic Preliminary Design of Bridges with Prestressed I-Girders.” J. Bridge Engineering ASCE 1 (1): 18-25.

[18] Sirca, G. F., and Adeli, H. 2005. "Cost Optimization of Prestressed Concrete Bridges." Journal of Structural Engineering 131: 380-8.

[19] Perea, C., Baitsch, M., Vidosa, F. G., and Hartmann, D. 2007. "Optimization of Reinforced Concrete Frame Bridges by Parallel Genetic and Memetic Algorithms." Presented at the Third International Conference on Structural Engineering, Mechanics and Computation 3, Cape Town, South Africa.

[20] Perea, C., Baitsch, M., Vidosa, F. G., and Hartmann, D. 2008. "Design of Reinforced Concrete Bridge Frames by Heuristic Optimization." J. Advances in Engineering Software 39: 676-88.

[21] Martí, J. V., and Vidosa, F. G. 2010. "Design of Prestressed Concrete Precast Pedestrian Bridges by Heuristic Optimization." J. Advances in Engineering Software 41: 916-22.

[22] Perea, C., Yepes, V., Alcala, J., Hospitaler, A., and Vidosa, F. G. 2010. "A Parametric Study of Optimum Road Frame Bridges by Threshold Acceptance." Indian Journal of Engineering \& Material Sciences 17: 427-37.

[23] Kolda, T. G., Lewis, R. M., and Torczon, V. 2003. "Optimization by Direct Search: New Perspectives on Some Classical and Modern Methods." SIAM Review 45 (3): 385-482.

[24] Storn, R., and Price, K. 1997. "Differential Evolution-A Simple and Efficient Heuristic for Global Optimization over Continous Spaces.” Journal of Global Optimization 11 (4): 341-59.

[25] Hooke, R., and Jeeves, T. A. 1960. "Direct Search Solution of Numerical and Statistical Problems." Journal of the ACM 8 (2): 212-29.

[26] The MathWorks Inc. 2012. Global Optimization Toolbox User's Guide. Natick, MA: The MathWorks Inc.

[27] Holland, J. H. 1992. "Genetic Algorithms: Computer Programs That Evolve in Ways That Resmeble Natural Selection Can Solve Complex Problems Even Their Creators Do Not Fully Understand." Scientific American July: 66-72.

[28] Haupt, R. L., and Haupt, S. E. 2004. Practical Genetic Algorithms. Hoboken, New Jersey: A John Wiley \& Sons, Inc. Publication.

[29] Balling, R. J., and Yao X. 1997. "Optimization of Reinforced Concrete Frames.” J. Struct. Eng. 123: 193-202.

[30] European Committee for Standardization. 2002. European Standards (Eurocodes), Parts 1 to 9. European Committee 
for Standardization.

[31] The Swedish Transport Administration (Trafikverket). 2011. TRVK Bro 11: Technical Requirements for Bridges, publ. Nr 2011:085. Sweden: The Swedish Transport Administration.

[32] Bengtlars, A., and Väljamets, E. 2014. "Optimization Of Pile Groups-A Practical Study Using Genetic Algorithm and Direct Search with Four Different Objective Functions." Master thesis, Royal Institute of Technology, Stockholm, Sweden.

[33] Bridge and Tunnel Management (BaTMan). 2016. "Portal of the Swedish Transport Administration (Trafikverket)." Accessed August 20, 2016. https://batman.trafikverket.se/ externportal. 